\title{
Stressful life events, social health issues and low birthweight in an Australian population-based birth cohort: challenges and opportunities in antenatal care
}

Stephanie J Brown ${ }^{1,2^{*}}$, Jane S Yelland ${ }^{1}$, Georgina A Sutherland ${ }^{1}$, Peter A Baghurst ${ }^{3}$ and Jeffrey S Robinson ${ }^{3}$

\begin{abstract}
Background: Investment in strategies to promote 'a healthy start to life' has been identified as having the greatest potential to reduce health inequalities across the life course. The aim of this study was to examine social determinants of low birthweight in an Australian population-based birth cohort and consider implications for health policy and health care systems.

Methods: Population-based survey distributed by hospitals and home birth practitioners to $>8000$ women six months after childbirth in two states of Australia. Participants were women who gave birth to a liveborn infant in Victoria and South Australia in September/October 2007. Main outcome measures included stressful life events and social health issues, perceived discrimination in health care settings, infant birthweight.

Results: 4,366/8468 (52\%) of eligible women returned completed surveys. Two-thirds (2912/4352) reported one or more stressful life events or social health issues during pregnancy. Women reporting three or more social health issues $(18 \%, 768 / 4352)$ were significantly more likely to have a low birthweight infant (< 2500 grams) after controlling for smoking and other socio-demographic covariates (Adj $\mathrm{OR}=1.77,95 \% \mathrm{Cl} 1.1-2.8$ ). Mothers born overseas in non-English speaking countries also had a higher risk of having a low birthweight infant (Adj OR = 1.85, 95\% Cl 1.2-2.9). Women reporting three or more stressful life events/social health issues were more likely to attend antenatal care later in pregnancy $(\mathrm{OR}=2.06,95 \% \mathrm{Cl} 1.3-3.1)$, to have fewer antenatal visits $(\mathrm{OR}=2.17,95 \%$ $\mathrm{Cl}$ 1.4-3.4) and to experience discrimination in health care settings $(\mathrm{OR}=2.69,95 \% \mathrm{Cl} 2.2-3.3)$.

Conclusions: There is a window of opportunity in antenatal care to implement targeted preventive interventions addressing potentially modifiable risk factors for poor maternal and infant outcomes. Developing the evidence base and infrastructure necessary in order for antenatal services to respond effectively to the social circumstances of women's lives is long overdue.
\end{abstract}

\section{Background}

Several recent reports, including the Fair Society, Healthy Lives report (The Marmot Review) and World Health Organisation's Commission on Social Determinants of Health (CSDH) Closing the Gap in a Generation, have identified investment in strategies to promote 'a healthy start to life' as having the greatest potential to

\footnotetext{
* Correspondence: stephanie.brown@mcri.edu.au

${ }^{1}$ Healthy Mothers Healthy Families Research Group, Murdoch Childrens Research Institute, Melbourne, Australia

Full list of author information is available at the end of the article
}

reduce health inequalities across the life course [1-3]. 'Giving every child the best start in life' was nominated by the Marmot Review as the number one priority for implementation [1]. Central to this recommendation is the accumulating evidence to show that brain development is highly sensitive to external influences in utero and in early childhood, with potential life long effects $[4,5]$. Infants that are born preterm, small for gestational age and/or with a low birthweight have well documented increased health risks in childhood, with more recent evidence supporting effects continuing into later

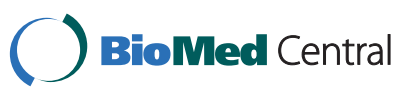

(C) 2011 Brown et al; licensee BioMed Central Ltd. This is an Open Access article distributed under the terms of the Creative Commons Attribution License (http://creativecommons.org/licenses/by/2.0), which permits unrestricted use, distribution, and reproduction in any medium, provided the original work is properly cited. 
life [6]. This research provides a powerful argument for supporting early intervention to improve maternal health in pregnancy and pre-conception as part of a comprehensive strategy to improve maternal, newborn and child health.

The major contribution of the CSDH Report and the Marmot Review is to situate this strategy within the broader context of health equity and the social determinants of health $[1,2]$. There is mounting evidence in both a developing and a developed country context, demonstrating higher prevalence of low birthweight and small for gestational age infants associated with individual and area-level measures of social adversity and deprivation [7-14]. Worse outcomes have been reported for 'blue collar workers' compared with 'white collar workers' $[10,12]$, lone parents $[8,11]$, low income households [11], and mothers living in deprived neighbourhoods $[11,13,14]$. A small number of studies have reported a positive association between low birthweight and stressful life events during or immediately preceding pregnancy $[15,16]$. Intimate partner violence, trait anxiety in the second and third trimester, and maternal distress in pregnancy also show associations with low birthweight [19-23]. Two potential pathways have been identified to explain these findings. The first posits that psychosocial factors such as stress or lack of social support impact on birth outcomes via neuroendocrine, immune or vascular mechanisms $[14,16,17]$. The second, more well-established pathway is via health behaviours which are known to be associated with increased risk such as smoking, maternal nutrition, infection and substance use [24].

The overall aim of this paper is to examine social determinants of low birthweight in an Australian population-based cohort and consider implications for health policy and health systems. The paper draws on data collected in an Australian population based survey of 4,366 women who gave birth in South Australia and Victoria to examine (i) the prevalence of stressful life events and social health issues in the 12 months before the birth, and (ii) women's experience of discrimination in health care settings as factors which may potentially contribute to poor infant health outcomes. To our knowledge, discrimination in maternal health care has not previously been investigated as a factor which may contribute to poor maternal and/or child health outcomes. Post hoc analyses are reported examining associations with attendance at antenatal care and with infant birthweight.

\section{Method}

\section{Sample}

The 2008 Healthy Mothers Healthy Families (HMHF) Survey questionnaire was mailed to women giving birth in two Australian states (Victoria and South Australia) in September/October 2007 at five to six months postpartum, excluding those who had a stillbirth, or whose baby was known to have died. Public and private maternity hospitals and homebirth practitioners in both states distributed questionnaires to women who gave birth under their care in the study period. All hospitals with births in the study period $(n=110)$ agreed to participate, however one small public hospital with approximately 90 confinements in the study period subsequently withdrew. Together South Australia and Victoria accounted for greater than $31 \%$ of the 289,496 births in Australia in 2007 [25]. The inclusion of two states provided for greater diversity in the sampled population compared with previous Victorian surveys [26-28]. Compared with Victoria, South Australia has a higher proportion of births to women living in outer regional (11.8\% versus $4.2 \%)$ and remote/very remote areas (3.9\% versus $0 \%$ ), a higher proportion of Aboriginal mothers (3.0\% versus $1.0 \%$ ) and women giving birth under 20 years (4.6\% versus $2.6 \%$ ), while Victoria has a higher proportion of births to women born overseas (26.6\% versus $16.3 \%$ ) [25].

\section{Procedure}

The primary aim of the study was to assess women's views and experiences of care received during pregnancy, birth and the postnatal period in representative samples of women giving birth in South Australia and Victoria in 2007. Questionnaires, together with a covering letter inviting women to take part, an explanation of the study in six community languages (Arabic, Vietnamese, Cantonese, Mandarin, Somali and Turkish) and a reply paid envelope for returning the questionnaire free of charge, were posted to women at six months postpartum. Two reminders were sent at two-week intervals with the second including a repeat copy of the questionnaire. The timing of the survey at five to six months postpartum matches previous Victorian surveys [26-28] and was decided taking into account the literature suggesting a 'halo' effect in relation to reporting of women's experiences of maternity care in the period immediately after childbirth [27] and the inclusion of questions on postpartum maternal health outcomes (e.g. maternal depression, urinary incontinence). A copy of the questionnaire is available on the study website: http:// www.mcri.edu.au/HMHFSurvey. The study period - four weeks in September 2007 in Victoria, and eight weeks in September/October 2007 in South Australia - was chosen to ensure sub-groups of interest (e.g. women attending six main models of care, women $<25$ years, single women, and women whose infant was $<2,500$ grams at birth) were large enough for meaningful statistical comparisons.

\section{Questionnaire}

Information was collected on women's views and experiences of care, health service use, maternal sociodemographic characteristics, reproductive history, and 
maternal and infant health outcomes, including infant birthweight. The questionnaire also included questions on maternal smoking in pregnancy, maternal pre-pregnant weight and height, and stressful life events and social health issues in the 12 months before the index birth. Measures of socio-economic status included: pretax household income adjusted for household size and composition, possession of a current health care concession card and health insurance status (private cover/ Medicare only). Women were classified as being at higher risk of complications in pregnancy if they had a previous low birthweight infant, preterm birth, or stillbirth, or if they had any substantial medical or obstetric risk factors in the current pregnancy (e.g. multiple pregnancy, gestational diabetes). Maternal pre-pregnant Body Mass Index (BMI) was calculated as the ratio of body weight in kilograms divided by the square of height in metres. Smoking status was assessed using a multiple response question enabling women to indicate if they had never smoked, quit smoking before their pregnancy, quit since the beginning of pregnancy, cut down cigarette smoking since finding out they were pregnant, continued to smoke at about the same level or increased their smoking since the beginning of pregnancy [29]. Women who said they had quit before pregnancy or never smoked were categorised as nonsmokers. Women who said they quit when they found out they were pregnant were categorised as smoking in early pregnancy; women who cut down, increased or continued to smoke about the same number of cigarettes as before their pregnancy were categorised as continuing to smoke throughout their pregnancy.

Assessment of stressful life events and social health issues drew on items included in the PRAMS study [30] with additional items incorporated based on results of a pilot survey and consultations with Aboriginal community organisations and communities in the two states. Women were asked "Did any of the following things happen to you in the 12 months before your new baby was born?" and invited to tick 'yes' or 'no' to 23 items including major life events, such as separation and divorce, moving house, losing your job, death of a close family member or friend and social health issues, such as having a lot of bills you couldn't pay, not having enough money to buy food, legal troubles or being involved in a court case, serious family conflict or being homeless. A complete list is provided in an additional file (see Additional File 1). Perceived discrimination was assessed using five questions (see Additional File 1) adapted from the Measure of Indigenous Racism Experience [31] to elicit information about women's experience of being discriminated against by health professionals in the perinatal period. The questions were designed to capture the concept of being 'treated unfairly', that is being treated as inferior, with less respect or courtesy, or receiving poorer care than other people. Women were also asked if they had been insulted, stereotyped, talked down to or ignored. Although based on a measure originally designed to assess racial discrimination, the questions were framed to illicit experiences of perceived discrimination in a variety of other contexts, for example, in relation to maternal age, education and other social characteristics.

The study was approved by the Royal Children's Hospital Human Research Ethics Committee (HREC), Victorian Department of Human Services HREC, South Australian Department of Health HREC and a number of other university and hospital based HRECs.

\section{Analysis}

Data on the social and obstetric characteristics of study participants were compared with routinely collected Victorian and South Australian perinatal data for all women who gave birth in the study period in order to assess the representativeness of the sample. Reporting of stressful life events and social health issues was categorised according to whether women reported no social health issues, one or two issues, or three or more issues. Data on discrimination were dichotomised to distinguish women who reported any experience of discrimination from those who reported never experiencing any of the kinds of discrimination we asked about. Data were analysed using STATA version 11.0 [32] and involved the calculation of unadjusted and adjusted odds ratios and 95\% confidence intervals. Multivariable logistic regression was used to assess the relationship between number of stressful life events and social health issues as the exposure of main interest (categorised as none, one to two issues, three or more issues) and low birthweight as the primary outcome variable. Four models are reported adjusting for: maternal smoking, social characteristics, number of antenatal visits and medical risk.

\section{Results}

Questionnaires were mailed to 8,597 women. The adjusted response fraction excluding a small number of questionnaires ( $\mathrm{n}=129$ ) 'returned to sender', duplicate responses and women who gave birth outside the study period was 52\% (4366/8468).

\section{Social characteristics and risk factors}

Table 1 shows the social and obstetric characteristics of participants compared with all Victorian and South Australian women who gave birth in the study period according to routinely collected perinatal data for both states. The mean age of women in the sample was 31 years (range 16 to 46 years). Comparisons with routinely collected data showed that women taking part in the 
Table 1 Social and obstetric characteristics of participants in the 2008 HMHF Survey and all women who gave birth in Victoria and South Australia during the study period*

\begin{tabular}{|c|c|c|c|c|}
\hline & \multicolumn{2}{|c|}{ HMHF Survey participants } & \multicolumn{2}{|c|}{$\begin{array}{l}\text { All women who gave birth } \\
\text { in study period }\end{array}$} \\
\hline & No. & $\%$ & No. & $\%$ \\
\hline \multicolumn{5}{|l|}{ Maternal age } \\
\hline$\leq 24$ years & 416 & 9.9 & 1385 & 16 \\
\hline $25-29$ years & 1053 & 25 & 2301 & 26.7 \\
\hline 30-34 years & 1604 & 38.1 & 2928 & 33.8 \\
\hline$\geq 35$ years & 1138 & 27 & 2035 & 23.5 \\
\hline \multicolumn{5}{|l|}{ Relationship status } \\
\hline Married or living with partner & 4201 & 95.5 & 7573 & 87.6 \\
\hline Single & 144 & 3.3 & 977 & 11.3 \\
\hline Divorced, separated or widowed & 55 & 1.2 & 88 & 1.1 \\
\hline \multicolumn{5}{|c|}{ Equivalised household income (before tax) per annum (AUD) } \\
\hline$\leq \$ 20,000$ & 938 & 24.2 & \multicolumn{2}{|c|}{ Not collected } \\
\hline$\$ 21,000-\$ 40,000$ & 1959 & 50.5 & & \\
\hline$\geq \$ 41,001$ & 979 & 25.3 & & \\
\hline \multicolumn{5}{|l|}{ Health care concession card } \\
\hline Yes & 949 & 21.9 & \multicolumn{2}{|c|}{ Not collected } \\
\hline No & 3394 & 78.2 & & \\
\hline \multicolumn{5}{|l|}{ Educational attainment (secondary) } \\
\hline Completed secondary school & 3429 & 79.3 & \multicolumn{2}{|c|}{ Not collected } \\
\hline Did not complete secondary school & 894 & 20.7 & & \\
\hline \multicolumn{5}{|l|}{ Educational attainment (tertiary) } \\
\hline Completed tertiary education & 2582 & 60 & \multicolumn{2}{|c|}{ Not collected } \\
\hline Did not complete tertiary education & 1722 & 40 & & \\
\hline \multicolumn{5}{|l|}{ Mother's Country of birth } \\
\hline Australia & 3521 & 81.5 & 6605 & 76.3 \\
\hline Overseas - English speaking & 272 & 6.3 & 478 & 5.6 \\
\hline Overseas - Non-English speaking & 526 & 12.2 & 1567 & 18.1 \\
\hline \multicolumn{5}{|c|}{ Risk of medical complications in pregnancy } \\
\hline Higher risk & 1712 & 39.2 & \multicolumn{2}{|c|}{ Not available in both states } \\
\hline Lower risk & 2654 & 60.8 & & \\
\hline \multicolumn{5}{|l|}{ Smoking in pregnancy } \\
\hline Yes & 752 & 17.6 & \multicolumn{2}{|c|}{ Not available in both states } \\
\hline No & 3516 & 82.4 & & \\
\hline \multicolumn{5}{|l|}{ Maternal pre-pregnant BMI } \\
\hline Underweight $(<18.5)$ & 182 & 4.5 & \multicolumn{2}{|c|}{ Not available in both states } \\
\hline Normal weight (18.5-24.9) & 2400 & 58.9 & & \\
\hline Overweight (25.0-29.9) & 909 & 22.3 & & \\
\hline Obese $(\geq 30)$ & 583 & 14.3 & & \\
\hline \multicolumn{5}{|c|}{ Social health issues/stressful life events ( 12 months before birth) } \\
\hline None & 1440 & 33.1 & \multicolumn{2}{|c|}{ Not available in both states } \\
\hline One to two issues & 2144 & 49.3 & & \\
\hline$\geq 3$ issues & 768 & 17.7 & & \\
\hline \multicolumn{5}{|l|}{ Parity } \\
\hline First baby & 1941 & 44.5 & 3609 & 41.6 \\
\hline Second or subsequent baby & 2425 & 55.5 & 5060 & 58.4 \\
\hline Infant birthweight & & & & \\
\hline$<2500 \mathrm{~g}$ & 179 & 4.1 & 565 & 6.5 \\
\hline $2500 \mathrm{~g}-3999 \mathrm{~g}$ & 3413 & 78.2 & 7183 & 81.9 \\
\hline$\geq 4000 \mathrm{~g}$ & 560 & 13.5 & 1019 & 11.6 \\
\hline
\end{tabular}

*Data on all women who gave birth in the study period obtained from the Victorian Perinatal Data Collection Unit and South Australian Pregnancy Outcome Unit; totals vary because of missing values. 
survey were largely representative in terms of key obstetric characteristics including parity, method of birth, and infant birthweight, but included fewer women born overseas of non-English speaking background, Aboriginal and Torres Strait Islander women, single women and women under 25 years. Eighteen percent of women reported smoking in pregnancy, including women who said that they quit or cut down smoking while pregnant. One third of participants who provided data on height and weight prior to pregnancy were overweight (25.0$29.9)$ or obese $(\geq 30)$. Two-thirds of women reported one or more stressful life events or social health issues during pregnancy, and $17 \%$ reported three or more issues.

\section{Stressful life events and social health issues}

Table 2 summarises data on associations between maternal social characteristics and stressful life events/ social health issues experienced in the 12 months before the birth. Maternal characteristics that were associated with substantially raised odds of reporting three or more stressful life events or social health issues were: being under 25 years; single, divorced or widowed; having a below average equivalised income; not completing year 12; smoking at any stage of pregnancy; being underweight (BMI <18.5); being at higher risk of obstetric complications, and being of Aboriginal and/or Torres Strait Islander origin.

\section{Experiences of discrimination in health care settings}

Women were significantly more likely to report experiencing discrimination if they were: under 25 years, had a low income, had not completed year 12, were not married, had a very high $(\geq 35)$ or a very low BMI $(<18.5)$, quit smoking in pregnancy or smoked throughout pregnancy and if they were at higher risk of medical complications. Women who reported three or more stressful life events/social health issues were significantly more likely to report discrimination $(314 / 760,41.3 \%$ versus $296 / 1429,20.7 \%$, OR $=2.69,95 \%$ CI 2.2-3.3). Women who reported one or two stressful life events/ social health issues also had significantly raised odds of experiencing discrimination $(518 / 2123,24.6 \%$ versus $20.7 \%$, OR $=1.2,95 \%$ CI 1.1-1.4) suggesting a 'dose response'.

\section{Patterns of health service use}

Despite the existence of universal health cover via Medicare, uptake of antenatal care varied in relation to maternal social characteristics and the number of stressful life events or social health issues women were coping with. Younger women, those who had below average household income, women who had not completed year 12 , women without a partner and women who smoked throughout pregnancy were more likely to attend a first antenatal check-up at $\geq 13$ weeks' gestation, and to attend less than five visits (Table 3 ). Women who reported stressful life events or social health issues were also more likely to attend late, and to attend fewer visits.

\section{Associations with low birthweight}

Univariable associations between maternal characteristics and low birthweight $(<2500)$ are shown in Table 4. Women at higher risk of obstetric complications in pregnancy had a fourfold increase in odds of having a low birthweight infant. Other maternal factors significantly associated with low birthweight were: not completing secondary education, being born overseas, and having a low pre-pregnant BMI $(<18.5)$. Women reporting three or more stressful life events or social health issues had a twofold increase in odds of having a baby with a low birthweight compared with women reporting no social health issues.

In order to obtain a more precise estimate of the association between low birthweight and the number of stressful life events and social health issues, we developed the four models shown in Table 5. Maternal smoking status was fitted in all models for a priori reasons based on the known aetiological relationship between maternal smoking and infant birthweight. The first model adjusts for maternal smoking alone, and shows that the association between number of stressful life events and social health issues and low birthweight remains statistically significant after adjusting for maternal smoking in pregnancy. Model 2 adjusts for other socio-demographic factors associated with the exposure of main interest (three or more social health issues) and the outcome variable (low birthweight) in univariable analyses. Models 3 and 4 include smoking status and all of the socio-demographic variables included in model 2, and adjust separately for number of antenatal visits (model 3) and risk of complications in pregnancy (model 4). All models indicate a dose effect related to number of stressful life events and social health issues. All models that fitted maternal country of birth indicated that women born overseas in non-English speaking countries had significantly raised odds of having a low birthweight infant.

\section{Discussion}

Over 30 years ago Archie Cochrane noted that antenatal care had escaped critical assessment in terms of content [33]. There is still a paucity of research evaluating the effectiveness of antenatal interventions specifically targeting modifiable risk factors for poor maternal and/or child health outcomes [34-36]. Recent efforts to improve the evidence base for antenatal care have focused on clinical care, smoking cessation support and on assessment of recommended visit schedules [37-40]. The 
Table 2 Relationship between stressful life events/social health issues, perceived discrimination and social and obstetric characteristics

\begin{tabular}{|c|c|c|c|c|c|c|c|}
\hline & $\begin{array}{c}\text { No } \\
\text { social } \\
\text { health } \\
\text { issues } \\
\text { No. (\%) }\end{array}$ & $\begin{array}{l}\text { One to two } \\
\text { social } \\
\text { health } \\
\text { issues } \\
\text { No. }(\%)\end{array}$ & $\begin{array}{c}\text { Three or more social } \\
\text { health issues } \\
\text { No. (\%) }\end{array}$ & $\begin{array}{l}\text { Odds Ratio } \\
(95 \% \mathrm{Cl})^{*}\end{array}$ & $\begin{array}{l}\text { Never experienced } \\
\text { discrimination } \\
\text { No. (\%) }\end{array}$ & $\begin{array}{c}\text { Experienced } \\
\text { discrimination } \\
\text { No. (\%) }\end{array}$ & $\begin{array}{l}\text { Odds } \\
\text { Ratio } \\
(95 \% \\
\mathrm{Cl})^{* *}\end{array}$ \\
\hline \multicolumn{8}{|l|}{ Maternal age } \\
\hline$\leq 24$ years & $84(20.3)$ & $166(40.2)$ & $163(39.5)$ & $\begin{array}{l}4.48 \\
(3.4-5.9)\end{array}$ & $250(60.7)$ & $162(39.3)$ & $\begin{array}{l}2.00 \\
(1.6-2.5)\end{array}$ \\
\hline$\geq 25$ years & $1315(34.7)$ & $1900(50.2)$ & $570(15.1)$ & 1.00 ref & $2853(75.6)$ & $923(24.4)$ & 1.00 ref \\
\hline \multicolumn{8}{|l|}{$\begin{array}{l}\text { Adjusted household } \\
\text { income (AUD) }\end{array}$} \\
\hline$<\$ 20,000$ & $239(25.6)$ & $400(42.9)$ & $296(31.7)$ & $\begin{array}{l}2.95 \\
(2.4-3.7)\end{array}$ & $619(66.5)$ & $312(33.5)$ & $\begin{array}{l}1.50 \\
(1.3-1.8)\end{array}$ \\
\hline$\$ 20,000-\$ 40,000$ & $684(35.0)$ & $983(50.3)$ & $287(14.7)$ & 1.00 ref & $1463(74.9)$ & $490(25.1)$ & 1.00 ref \\
\hline$>\$ 40,000$ & $364(37.3)$ & $524(53.7)$ & $88(9.0)$ & $\begin{array}{l}0.58 \\
(0.4-0.8) \\
\end{array}$ & $764(78.0)$ & $215(22.0)$ & $\begin{array}{l}0.84 \\
(0.7-1.0) \\
\end{array}$ \\
\hline \multicolumn{8}{|l|}{ Educational attainment } \\
\hline Completed Yr 12 & $1152(33.7)$ & 1739 (50.9) & $529(15.5)$ & 1.00 ref & $2556(74.9)$ & $856(25.1)$ & 1.00 ref \\
\hline Did not complete Yr 12 & $272(30.6)$ & $390(43.8)$ & $228(25.6)$ & $\begin{array}{l}1.83 \\
(1.5-2.3)\end{array}$ & $617(69.6)$ & $270(30.4)$ & $\begin{array}{l}1.31 \\
(1.1-1.5)\end{array}$ \\
\hline \multicolumn{8}{|l|}{ Indigenous status } \\
\hline $\begin{array}{l}\text { Not Aboriginal and/or } \\
\text { Torres Strait Islander }\end{array}$ & $1328(33.2)$ & $1999(50.1)$ & $713(16.7)$ & 100 ref & 2968 (73.6) & $1067(26.4)$ & 1.00 ref \\
\hline $\begin{array}{l}\text { Aboriginal and/or Torres } \\
\text { Strait Islander }\end{array}$ & $8(25.8)$ & $11(35.5)$ & $12(38.7)$ & $\begin{array}{l}2.79 \\
(1.1-6.9) \\
\end{array}$ & $21(67.7)$ & $10(32.3)$ & $\begin{array}{l}1.32 \\
(0.6-2.8) \\
\end{array}$ \\
\hline \multicolumn{8}{|l|}{$\begin{array}{l}\text { Maternal country of } \\
\text { birth }\end{array}$} \\
\hline Australia & 1165 (33.2) & $1716(48.8)$ & $633(18.0)$ & 1.00 ref & $2604(74.2)$ & $906(25.8)$ & 1.00 ref \\
\hline $\begin{array}{l}\text { Overseas - English } \\
\text { speaking }\end{array}$ & $82(30.5)$ & $149(55.4)$ & $38(14.1)$ & $\begin{array}{l}0.85 \\
(0.5-1.3)\end{array}$ & $195(72.0)$ & $76(28.0)$ & $\begin{array}{l}1.12 \\
(0.8-1.5)\end{array}$ \\
\hline $\begin{array}{l}\text { Overseas - Non English } \\
\text { speaking }\end{array}$ & $178(34.0)$ & $258(49.3)$ & $87(16.6)$ & $\begin{array}{l}0.90 \\
(0.7-1.2)\end{array}$ & $381(73.1)$ & $140(26.9)$ & $\begin{array}{l}1.06 \\
(0.8-1.3) \\
\end{array}$ \\
\hline \multicolumn{8}{|l|}{ Relationship status } \\
\hline Married & $1181(35.7)$ & $1696(51.2)$ & $437(12.2)$ & 1.00 ref & $2511(76.3)$ & $779(23.7)$ & 1.00 ref \\
\hline Living with partner & $236(28.3)$ & $379(46.8)$ & $219(26.3)$ & $\begin{array}{l}2.51 \\
(2.0-3.1)\end{array}$ & $555(66.9)$ & $274(33.1)$ & $\begin{array}{l}1.59 \\
(1.3-1.9)\end{array}$ \\
\hline Single/divorce/separated & $20(10.4)$ & $61(38.5)$ & $111(57.8)$ & $\begin{array}{l}15.0 \\
(9.2-24.4) \\
\end{array}$ & 119 (62.6) & $71(37.4)$ & $\begin{array}{l}1.92 \\
(1.4-2.6) \\
\end{array}$ \\
\hline \multicolumn{8}{|l|}{$\begin{array}{l}\text { Maternal pre-pregnant } \\
\text { BMI }\end{array}$} \\
\hline Underweight $(<18.5)$ & $46(25.3)$ & $91(50.0)$ & $45(24.7)$ & $\begin{array}{l}2.08 \\
(1.4-3.2)\end{array}$ & $121(68.0)$ & $57(32.0)$ & $\begin{array}{l}1.44 \\
(1.0-2.0)\end{array}$ \\
\hline Normal weight (18.5-24.9) & $814(34.0)$ & $1197(50.0)$ & $382(16.0)$ & 1.00 ref & $1802(75.5)$ & $586(24.5)$ & 1.00 ref \\
\hline Overweight (25-29.9) & $308(34.0)$ & $435(48.1)$ & $162(17.9)$ & $\begin{array}{l}1.12 \\
(0.9-1.4)\end{array}$ & $669(74.0)$ & $235(26.0)$ & $\begin{array}{l}1.08 \\
(0.9-1.3)\end{array}$ \\
\hline Obese $(\geq 30)$ & $184(31.6)$ & $284(48.7)$ & $115(19.7)$ & $\begin{array}{l}1.33 \\
(1.0-1.7)\end{array}$ & $412(71.0)$ & $168(29.0)$ & $\begin{array}{l}1.25 \\
(1.0-1.5) \\
\end{array}$ \\
\hline \multicolumn{8}{|l|}{$\begin{array}{l}\text { Smoking during } \\
\text { pregnancy }\end{array}$} \\
\hline Non-smoker & $1232(35.1)$ & $1760(50.2)$ & $514(14.7)$ & 1.00 ref & $2623(75.2)$ & $864(24.8)$ & 1.00 ref \\
\hline Quit in pregnancy & $95(27.1)$ & $169(48.2)$ & $87(24.8)$ & $\begin{array}{l}2.20 \\
(1.6-3.0)\end{array}$ & $248(71.5)$ & 99 (28.5) & $\begin{array}{l}1.21 \\
(0.9-1.5)\end{array}$ \\
\hline $\begin{array}{l}\text { Smoking throughout } \\
\text { pregnancy }\end{array}$ & $86(21.5)$ & $162(40.5)$ & $152(38.0)$ & $\begin{array}{l}4.24 \\
(3.2-5.6)\end{array}$ & $245(62.0)$ & $150(38.0)$ & $\begin{array}{l}1.86 \\
(1.5-2.3)\end{array}$ \\
\hline \multicolumn{8}{|l|}{ Medical risk } \\
\hline Lower risk & $960(36.3)$ & $1295(48.9)$ & $392(14.8)$ & 1.00 ref & 2008 (76.3) & 624 (23.7) & 1.00ref \\
\hline
\end{tabular}


Table 2 Relationship between stressful life events/social health issues, perceived discrimination and social and obstetric characteristics (Continued)

\begin{tabular}{|c|c|c|c|c|c|c|c|}
\hline Higher risk & $480(28.2)$ & $849(49.8)$ & $376(22.1)$ & $\begin{array}{l}1.92 \\
(1.6-2.3)\end{array}$ & $1184(70.0)$ & $508(30.0)$ & $\begin{array}{l}1.38 \\
(1.2-1.6) \\
\end{array}$ \\
\hline \multicolumn{8}{|l|}{ Gestation } \\
\hline$\geq 37$ weeks & $1333(33.7)$ & $1939(49.0)$ & $686(17.33)$ & 1.00 ref & $2913(74.1)$ & $1020(25.9)$ & 1.00 ref \\
\hline$<37$ weeks & 79 (28.3) & $146(52.3)$ & $54(19.4)$ & $\begin{array}{l}1.32 \\
(0.9-1.9)\end{array}$ & $198(71.2)$ & $80(28.8)$ & $\begin{array}{l}1.15 \\
(0.9-1.5)\end{array}$ \\
\hline \multicolumn{8}{|c|}{ Infant birthweight } \\
\hline$\geq 2500$ grams & 1332 (33.6) & $1954(49.3)$ & $676(17.1)$ & 1.00 ref & $2903(73.8)$ & $1032(26.2)$ & 1.00 ref \\
\hline$<2500$ grams & $44(24.7)$ & $88(49.4)$ & $46(25.8)$ & $\begin{array}{l}2.06 \\
(1.3-3.1)\end{array}$ & $121(68.0)$ & $57(32.0)$ & $\begin{array}{l}1.32 \\
(1.0-1.8)\end{array}$ \\
\hline
\end{tabular}

*Odds ratios in this column refer to comparisons between women who experienced $\geq 2$ stressful life events with those who experienced no events.

**Odds ratios in the last column refer to comparisons between women who experienced discrimination with those reporting no discrimination.

relationship between the content and organisation of antenatal care and subsequent maternal and child health outcomes has received scant attention [36]. For example, scientific knowledge about the extent to which different approaches to care (e.g. model of maternity care, pregnancy outreach workers) may influence nutrition, exercise habits, oral health, smoking, drug use, choices regarding infant feeding method, maternal depression or anxiety, intimate partner violence, inter pregnancy interval, and post pregnancy use of health services is negligible.

Our findings from a large Australian population-based survey of recent mothers attest to the high prevalence of potentially modifiable risk factors such as smoking and overweight and obesity. They also highlight a concerning level of social adversity associated with stressful life events and social health issues co-occurring with pregnancy. One in six women reported three or more stressful life events or social health issues in the 12 months before the birth. These women were much more likely to perceive that they were discriminated against in health care settings, to attend later in pregnancy and to have fewer antenatal visits. Women coping with multiple life events or social health issues remain significantly more likely to have a low birthweight infant when maternal smoking, number of antenatal visits, and other covariates are taken into account. Interpretation of the relationship between timing and number of antenatal visits and infant birthweight is complex. Our data show that some groups of women are less likely to access antenatal care early, and to attend regularly during pregnancy. The same groups of women are more likely to have adverse outcomes. This does not signify causation, but it does suggest that women who most need care and support during pregnancy are more likely to not to engage with services.

Several study limitations need to be considered. First, we used a modified life events scale originally developed for use in pregnancy [41] that has also been used in large scale maternity surveys in the United States and
Canada [16,30,42]. Modifications made based on piloting and consultations preceding implementation of the HMHF Survey have not been subject to psychometric testing. Nor have we sought in this paper to differentiate different types of stressors. Our primary aim was to assess the association between low birthweight and number of stressful life events and social health issues and consider potential implications for the care of women during pregnancy. Consideration of broader questions regarding the relationship between different types of stress in pregnancy and area level deprivation are beyond the scope of analyses presented in the paper.

Second, it is plausible that women having a low birthweight infant may be more inclined to recall adverse life events in pregnancy than women who have an infant of higher birthweight, although this potential source of bias may have been lessened by the time elapsed between the birth and completing the survey at around six months postpartum. Third, we were not able to validate maternal recall of infant birthweight or maternal smoking in pregnancy. Validation studies comparing mothers' accounts of infant birthweight with medical records have shown high levels of agreement for this outcome as opposed to gestation, where there are more mixed findings $[43,44]$. This was the reason for reporting infant birthweight, rather than small for gestational age. We acknowledge the potential for misclassification of maternal smoking status in early and late pregnancy. However, our finding that $17.6 \%$ of study participants reported smoking in pregnancy is in accord with routinely collected data available for seven Australian states and territories in 2007 which indicate that $16.6 \%$ of women smoked in pregnancy [25]. We used a multiple response format for seeking information about maternal smoking which has been shown to improve disclosure of maternal smoking in self-administered questionnaires [29]. Fourth, the sample while relatively large, provided low numbers in sub-groups for some comparisons (e.g. single women, Indigenous women). 
Table 3 Risk factors by pattern of health service use

\begin{tabular}{|c|c|c|c|c|c|c|c|}
\hline & \multicolumn{3}{|c|}{ Timing of first antenatal visit } & \multicolumn{4}{|c|}{ Number of antenatal visits } \\
\hline & $\begin{array}{l}\leq 12 \text { weeks' } \\
\text { gestation } \\
\text { No. }(\%)\end{array}$ & $\begin{array}{c}>12 \text { weeks' } \\
\text { gestation } \\
\text { No. (\%) }\end{array}$ & $\begin{array}{c}\text { Odds Ratio } \\
(95 \% \mathrm{Cl})\end{array}$ & $\begin{array}{c}<5 \text { visits } \\
\text { No. }(\%)\end{array}$ & $\begin{array}{l}\text { 5-8 visits } \\
\text { No. (\%) }\end{array}$ & $\begin{array}{c}>8 \text { visits } \\
\text { No. (\%) }\end{array}$ & $\begin{array}{l}\text { Odds Ratio } \\
(95 \% \mathrm{Cl})^{* *}\end{array}$ \\
\hline \multicolumn{8}{|l|}{ Maternal age } \\
\hline$\leq 24$ years & $365(88.2)$ & $49(11.8)$ & 1.00 ref & $29(7.3)$ & $168(42.4)$ & $199(50.3)$ & 1.00 ref \\
\hline$\geq 25$ years & $3597(95.2)$ & $180(4.8)$ & $\begin{array}{c}2.68 \\
(1.9-3.7)\end{array}$ & $144(3.9)$ & $1503(40.1)$ & $2048(55.4)$ & $\begin{array}{c}1.95 \\
(1.3-2.9)\end{array}$ \\
\hline \multicolumn{8}{|c|}{ Adjusted household income (AUD) } \\
\hline$<\$ 20,000$ & $839(89.7)$ & $96(10.3)$ & $\begin{array}{c}2.94 \\
(2.1-4.0)\end{array}$ & $53(5.9)$ & $412(45.6)$ & $439(48.6)$ & $\begin{array}{c}1.62 \\
(1.1-2.3)\end{array}$ \\
\hline$\$ 20,000-\$ 40,000$ & $1878(96.3)$ & $73(3.7)$ & 1.00 ref & $71(3.7)$ & $770(40.3)$ & $1072(56.0)$ & 1.00 ref \\
\hline$>\$ 40,000$ & $941(96.2)$ & $37(3.8)$ & $\begin{array}{c}1.01 \\
(0.7-1.5)\end{array}$ & $30(3.1)$ & $372(38.6)$ & $561(58.3)$ & $\begin{array}{c}0.83 \\
(0.5-1.3)\end{array}$ \\
\hline \multicolumn{8}{|l|}{ Educational attainment } \\
\hline Completed year 12 & $3243(94.9)$ & $173(5.1)$ & 1.00 ref & $118(3.5)$ & $1351(40.4)$ & $1875(56.1)$ & 1.00 ref \\
\hline Did not complete year 12 & $821(92.5)$ & $67(7.6)$ & $\begin{array}{c}1.53 \\
(1.1-2.0)\end{array}$ & $59(6.9)$ & $360(41.9)$ & $440(51.2)$ & $\begin{array}{c}2.02 \\
(1.5-2.8)\end{array}$ \\
\hline \multicolumn{8}{|l|}{ Maternal country of birth } \\
\hline Australia & $3330(94.8)$ & $182(5.2)$ & 1.00 ref & $129(3.7)$ & $1375(40.0)$ & $1936(56.3)$ & 1.00 ref \\
\hline Overseas - English speaking & $247(91.8)$ & $22(8.2)$ & $\begin{array}{c}1.63 \\
(1.0-2.6)\end{array}$ & $16(6.3)$ & $117(45.7)$ & $123(48.1)$ & $\begin{array}{c}1.71 \\
(1.0-2.9)\end{array}$ \\
\hline Overseas - Non-English speaking & $484(93.3)$ & $35(6.7)$ & $\begin{array}{c}1.32 \\
(0.9-1.9)\end{array}$ & $29(5.8)$ & $216(43.1)$ & $256(51.1)$ & $\begin{array}{c}1.58 \\
(1.0-2.4)\end{array}$ \\
\hline \multicolumn{8}{|l|}{ Relationship status } \\
\hline Married & $3155(95.7)$ & $143(4.3)$ & 1.00 ref & $118(3.6)$ & $1292(40.0)$ & $1821(56.4)$ & 1.00 ref \\
\hline Living with partner & $764(92.0)$ & $66(8.0)$ & $\begin{array}{c}1.9 \\
(1.4-2.6)\end{array}$ & $44(5.5)$ & $349(43.4)$ & $412(51.2)$ & $\begin{array}{c}1.52 \\
(1.0-2.2)\end{array}$ \\
\hline Single/divorced/separated & $161(84.3)$ & $30(15.7)$ & $\begin{array}{c}4.11 \\
(2.7-6.3)\end{array}$ & $16(8.9)$ & $76(42.2)$ & $88(48.9)$ & $\begin{array}{c}2.57 \\
(1.5-4.4)\end{array}$ \\
\hline \multicolumn{8}{|c|}{ Risk of complications in pregnancy } \\
\hline Lower risk & $2470(93.9)$ & $160(6.1)$ & 1.0 ref & $108(4.2)$ & $1147(44.8)$ & $1306(51.0)$ & 1.00 ref \\
\hline Higher risk & $1622(95.2)$ & $82(4.8)$ & $\begin{array}{c}0.78 \\
(0.6-1.0)\end{array}$ & $71(4.3)$ & $576(34.5)$ & $1022(61.2)$ & $\begin{array}{c}1.01 \\
(0.7-1.4)\end{array}$ \\
\hline \multicolumn{8}{|l|}{ Maternal pre-pregnant BMI } \\
\hline Underweight $(<18.5)$ & $167(92.8)$ & $13(7.2)$ & $\begin{array}{c}1.41 \\
(0.8-2.6)\end{array}$ & $8(4.6)$ & $67(38.3)$ & $100(57.1)$ & $\begin{array}{c}1.05 \\
(0.5-2.2)\end{array}$ \\
\hline Normal weight (18.5-24.9) & $2268(94.8)$ & $125(5.2)$ & 1.00 ref & $102(4.4)$ & $963(41.3)$ & $1266(54.3)$ & 1.00 ref \\
\hline Overweight (25.0-29.9) & $855(94.6)$ & $49(5.4)$ & $\begin{array}{c}1.04 \\
(0.7-1.5)\end{array}$ & $40(4.5)$ & $363(40.7)$ & $490(54.9)$ & $\begin{array}{c}1.02 \\
(0.7-1.5)\end{array}$ \\
\hline Obese $(\geq 30)$ & $546(94.0)$ & $35(6.0)$ & $\begin{array}{c}1.16 \\
(0.8-1.7)\end{array}$ & $15(2.6)$ & $226(39.7)$ & $328(57.6)$ & $\begin{array}{c}0.59 \\
(0.3-1.0)\end{array}$ \\
\hline \multicolumn{8}{|l|}{ Smoking in pregnancy } \\
\hline Non-smoker & $3310(94.8)$ & $181(5.2)$ & 1.00 ref & $124(3.6)$ & $1377(40.4)$ & $1906(55.9)$ & 1.00 ref \\
\hline Quit in pregnancy & $327(93.7)$ & $22(6.3)$ & $\begin{array}{c}1.23 \\
(0.8-1.9)\end{array}$ & $13(3.8)$ & $142(41.3)$ & $189(54.9)$ & $\begin{array}{c}1.04 \\
(0.6-1.9)\end{array}$ \\
\hline Smoking throughout pregnancy & $363(91.2)$ & $35(8.8)$ & $\begin{array}{c}1.76 \\
(1.2-2.6)\end{array}$ & $34(8.8)$ & $166(42.9)$ & $187(48.3)$ & $\begin{array}{c}2.55 \\
(1.7-3.8)\end{array}$ \\
\hline \multicolumn{8}{|c|}{ Stressful life events/social health issues } \\
\hline None & $1361(95.3)$ & $67(4.7)$ & 1.00 ref & $40(2.9)$ & $551(39.5)$ & $805(57.7)$ & 1.00 ref \\
\hline One to two issues & $2009(94.3)$ & $122(5.7)$ & $\begin{array}{c}1.36 \\
(0.9-2.0)\end{array}$ & $94(4.5)$ & $865(41.4)$ & $1130(54.1)$ & $\begin{array}{c}1.6 \\
(1.1-2.3)\end{array}$ \\
\hline$\geq 3$ issues & $709(93.0)$ & $53(7.0)$ & $\begin{array}{c}2.06 \\
(1.3-3.1)\end{array}$ & $44(6.0)$ & 301 (41.1) & 387 (52.9) & $\begin{array}{c}2.17 \\
(1.4-3.4)\end{array}$ \\
\hline
\end{tabular}

**Odds ratios in the last column refer to comparisons of women attending $<5$ visits with women attending $\geq 5$ visits. 
Table 4 Associations with infant birthweight

\begin{tabular}{|c|c|c|c|}
\hline & $\begin{array}{l}\geq 2500 \mathrm{~g} \\
\text { No. (\%) }\end{array}$ & $\begin{array}{l}<2500 \mathrm{~g} \\
\text { No. (\%) }\end{array}$ & OR $(95 \% \mathrm{Cl})$ \\
\hline \multicolumn{4}{|l|}{ Maternal age } \\
\hline$\leq 24$ years & $3467(95.8)$ & $151(4.2)$ & 1.00 ref \\
\hline$>24$ years & $376(95.4)$ & $18(4.6)$ & $1.10(0.7-1.8)$ \\
\hline \multicolumn{4}{|c|}{ Adjusted household income (AUD) } \\
\hline$<\$ 20,000$ & $830(95.7)$ & $37(4.3)$ & $1.00(0.7-1.5)$ \\
\hline$\$ 20,000-\$ 40,000$ & $1799(95.7)$ & $81(4.3)$ & 1.00 ref \\
\hline$>\$ 40,000$ & $904(95.9)$ & $39(4.1)$ & $1.00(0.6-1.4)$ \\
\hline \multicolumn{4}{|l|}{ Educational attainment } \\
\hline Completed year 12 & $3147(96.1)$ & $127(3.9)$ & 1.00 ref \\
\hline Did not complete year 12 & $789(94.0)$ & $50(6.0)$ & $1.57(1.1-2.2)$ \\
\hline \multicolumn{4}{|l|}{ Relationship status } \\
\hline Married & 3035 (95.7) & $135(4.3)$ & 1.00 ref \\
\hline Living with partner & $766(96.0)$ & $32(4.0)$ & $0.93(0.6-1.4)$ \\
\hline Single/divorced/separated & $160(93.0)$ & $12(7.0)$ & $1.69(0.9-3.1)$ \\
\hline \multicolumn{4}{|l|}{ Maternal Country of birth } \\
\hline Australia & $3230(96.1)$ & $130(3.9)$ & 1.00 ref \\
\hline Overseas - English speaking & $241(93.8)$ & $16(6.2)$ & $1.65(1.0-2.8)$ \\
\hline Overseas - Non-English speaking & $457(93.5)$ & $32(6.5)$ & $1.73(1.2-2.6)$ \\
\hline \multicolumn{4}{|c|}{ Risk of complications in pregnancy } \\
\hline Lower risk & $2473(98.1)$ & $49(1.9)$ & 1.00 ref \\
\hline Higher risk & $1500(92.0)$ & $130(8.0)$ & $4.37(3.1-6.1)$ \\
\hline \multicolumn{4}{|l|}{ Maternal pre-pregnant BMI } \\
\hline Underweight $(<18.5)$ & $163(92.6)$ & $13(7.4)$ & $1.74(1.0-3.2)$ \\
\hline Normal weight (18.5-24.9) & $2193(95.6)$ & $100(4.7)$ & 1.00 ref \\
\hline Overweight (25.0-29.9) & $837(96.0)$ & $35(4.0)$ & $0.92(0.6-1.4)$ \\
\hline Obese $(\geq 30)$ & $537(96.4)$ & $20(3.6)$ & $0.82(0.5-1.3)$ \\
\hline \multicolumn{4}{|l|}{ Smoking in pregnancy } \\
\hline Non-smoker & $3222(96.1)$ & $132(3.9)$ & 1. 00 ref \\
\hline Quit in pregnancy & $325(96.0)$ & $13(3.9)$ & $0.98(0.5-1.7)$ \\
\hline Smoking throughout pregnancy & $343(92.4)$ & $28(7.6)$ & $1.99(1.3-3.0)$ \\
\hline \multicolumn{4}{|c|}{ Stressful life events/social health issues } \\
\hline None & $1332(96.8)$ & $44(3.2)$ & 1.00 ref \\
\hline One to two issues & $1954(95.7)$ & $88(4.3)$ & $1.36(1.0-2.0)$ \\
\hline$\geq 3$ issues & $676(93.6)$ & $46(6.4)$ & $2.06(1.3-3.1)$ \\
\hline
\end{tabular}

Strengths of the study include a population-based sample drawn from two out of the eight Australian states and territories. The sampled population for the survey comprised 15\% of confinements in South Australia and 8\% in Victoria in 2007. While it is not possible to determine causal pathways in an observational study, the findings draw attention to social circumstances in women's lives that may place them at higher risk of poor perinatal and longer term outcomes. They also draw attention to vulnerable population groups who may be at additional risk.

\section{Conclusions}

Developing the infrastructure to support an integrated primary care approach to antenatal care in which services have the capacity to respond effectively to social circumstances in women's lives and to vulnerable populations is long overdue, and requires far reaching changes involving both hospital and community based services [45]. The recently released NICE clinical guideline on service provision for pregnant women with complex social factors provides an excellent starting point and practical recommendations focusing on four vulnerable population groups: pregnant women who misuse substances, young pregnant women, pregnant women experiencing intimate partner violence and pregnant women who are recent migrants, asylum seekers or refugees [46]. Another important area for intervention is pre-conception, 
Table 5 Multivariable logistic regression analyses assessing associations with low birthweight $(\mathbf{n}=3650)$

\begin{tabular}{|c|c|c|c|c|c|c|}
\hline & $\begin{array}{c}<2500 \text { grams } \\
\text { No. (\%) }\end{array}$ & $\begin{array}{l}\text { Unadjusted OR } \\
(95 \% \mathrm{Cl})\end{array}$ & $\begin{array}{c}\text { Model } 1 \\
\text { Adj OR } \\
(95 \% \mathrm{Cl})\end{array}$ & $\begin{array}{c}\text { Model } 2 \\
\text { Adj OR } \\
(95 \% \mathrm{Cl}) \mathrm{s}\end{array}$ & $\begin{array}{c}\text { Model } 3 \\
\text { Adj OR } \\
(95 \% \mathrm{Cl})\end{array}$ & $\begin{array}{c}\text { Model } 4 \\
\text { Adj OR } \\
(95 \% \mathrm{Cl})\end{array}$ \\
\hline \multicolumn{7}{|c|}{ Stressful life events/social health issues } \\
\hline No issues & $40(3.3)$ & 1.00 ref & 1.00 ref & 1.00 ref & 1.00 ref & 1.00 ref \\
\hline $1-2$ issues & $75(4.1)$ & $1.27(0.9-1.9)$ & $1.26(0.9-1.9)$ & $1.24(0.8-1.8)$ & $1.22(0.8-1.8)$ & $1.13(0.8-1.7)$ \\
\hline$\geq 3$ issues & $38(6.2)$ & $1.94(1.2-3.1)$ & $1.80(1.1-2.9)$ & $1.77(1.1-2.8)$ & $1.72(1.1-2.8)$ & $1.44(1.0-2.3)$ \\
\hline \multicolumn{7}{|l|}{ Smoking status } \\
\hline Non-smoker & $120(4.0)$ & 1.00 ref & 1.00 ref & 1.00 ref & 1.00 ref & 1.00 ref \\
\hline Quit in pregnancy & $9(3.0)$ & $0.76(0.4-1.5)$ & $0.72(0.36-1.4)$ & $0.69(0.3-1.4)$ & $0.71(0.4-1.4)$ & $0.67(0.3-1.3)$ \\
\hline Smoking throughout pregnancy & $24(7.5)$ & $1.97(1.3-3.1)$ & $1.76(1.1-2.8)$ & $1.75(1.1-2.8)$ & $1.57(1.0-2.6)$ & $1.82(1.1-3.0)$ \\
\hline \multicolumn{7}{|l|}{ Maternal country of birth } \\
\hline Australia & $113(3.8)$ & 1.00 ref & & 1.00 ref & 1.00 ref & 1.00 ref \\
\hline Overseas - English speaking & $13(5.8)$ & $1.58(0.9-2.8)$ & & $1.66(0.9-3.0)$ & $1.54(0.8-2.8)$ & $1.60(0.9-2.9)$ \\
\hline Overseas - Non-English speaking & $27(6.4)$ & $1.76(1.1-2.7)$ & & $1.85(1.2-2.9)$ & $1.80(1.1-2.8)$ & $1.90(1.2-3.0)$ \\
\hline \multicolumn{7}{|l|}{ Maternal pre-pregnant BMI } \\
\hline Underweight $(<18.5)$ & $11(6.8)$ & $1.62(0.8-3.1)$ & & $1.37(0.7-2.6)$ & $1.37(0.7-2.6)$ & $1.39(0.7-2.7)$ \\
\hline Normal weight (18.5-24.9) & $93(4.3)$ & 1.00 ref & & 1.00 ref & 1.00 ref & 1.00 ref \\
\hline Overweight (25-29.9) & $33(4.0)$ & $0.92(0.6-1.4)$ & & $0.92(0.6-1.4)$ & $0.94(0.6-1.4)$ & $0.81(0.5-1.2)$ \\
\hline Obese $(\geq 30)$ & $16(3.1)$ & $0.69(0.4-1.2)$ & & $0.69(0.4-1.2)$ & $0.72(0.4-1.2)$ & $0.54(0.3-0.9)$ \\
\hline \multicolumn{7}{|l|}{ Educational attainment } \\
\hline Completed year 12 & $113(3.9)$ & 1.00 ref & & 1.00 ref & 1.00 ref & 1.0 ref \\
\hline Did not complete year 12 & $40(5.4)$ & $1.46(1.0-2.1)$ & & $1.36(0.9-2.0)$ & $1.30(0.9-1.9)$ & $1.27(0.9-1.9)$ \\
\hline \multicolumn{7}{|l|}{ Number of antenatal visits } \\
\hline$\geq 5$ visits & $133(3.8)$ & 1.00 ref & & & 1.00 ref & \\
\hline$<5$ visits & $20(14.3)$ & $4.23(2.6-7.0)$ & & & $3.48(2.1-5.8)$ & \\
\hline \multicolumn{7}{|c|}{ Risk of complications in pregnancy } \\
\hline Lower risk & $40(1.8)$ & 1.00 ref & & & & 1.00 ref \\
\hline Higher risk & $113(7.9)$ & $4.72(3.3-6.8)$ & & & & $4.83(3.3-7.0)$ \\
\hline
\end{tabular}

Model 1: exposures of main interest adjusted for smoking status.

Model 2: exposure of main interest adjusted for smoking status, maternal country of birth, maternal BMI, maternal education.

Model 3: exposure of main interest adjusted for smoking status, maternal country of birth, maternal BMI, maternal education and number of antenatal visits.

Model 4: exposure of main interest adjusted for smoking status, maternal country of birth, maternal BMl, maternal education and risk of complications in pregnancy.

especially during adolescence and during early adulthood. There are major challenges for policy makers and health services in developing an appropriately skilled workforce; development of a life-course approach to promotion of maternal, newborn and child health that includes a focus on public health intervention during pregnancy and prior to conception; development of team work and collaboration within and across agencies; facilitating professional, consumer and community participation; and investment in monitoring and evaluation to ensure outcome based accountability. A shift in this direction requires fundamentally different thinking and co-ordinated action across sectors to bring about system wide changes $[47,48]$. Only if this challenge is embraced will health care services be capable of developing effective proactive approaches to potentially modifiable risks and health needs in diverse populations.

\section{Additional material}

Additional file 1: Measures of stressful life events and social health issues and perceived discrimination. A complete list of the items used in this survey to measure stressful life events and social health issues and the five questions adapted from the Measure of Indigenous Racism Experience to elicit information about women's experience of discrimination by health professionals in the perinatal period.

\section{Acknowledgements}

We are grateful to the thousands of women who participated in the survey at a particularly busy time in their lives; staff at the hospitals in South Australia and Victoria who assisted with mailing out the survey; to the following study investigators who contributed to development of the research protocol and conduct of the study: Mary-Anne Biro, Jane Gunn, Georgie Stamp and Euan Wallace; and to staff at the Healthy Mothers Healthy Families research group, especially those who have made a significant contribution to the conduct of the study: Penny Marlowe, Jenny Kelly, Jan Wiebe, Maggie Flood, Monique Keel, Catherine Chisholm. The study was funded by a National Health and Medical Research Council project grant ID: 433012 (2007-2010) and grants from the South Australian 
Department of Health (2007-2008) and Victorian Department of Human Services (2007-2008). All researchers are independent from these sources of funding. The study sponsors had no role in the study design, collection, analysis, and interpretation of data, the writing of the article, and the decision to submit it for publication.

\section{Author details}

${ }^{1}$ Healthy Mothers Healthy Families Research Group, Murdoch Childrens Research Institute, Melbourne, Australia. ${ }^{2}$ Department of General Practice and School of Population Health, University of Melbourne, Melbourne, Australia.

${ }^{3}$ Women's and Children's Hospital, University of Adelaide, Adelaide, Australia.

\section{Authors' contributions}

SB and JY conceived the study; PB and JR contributed to the study protocol and grant applications for the study; JY and PB supervised data collection; JY and GW are responsible for data management; GS undertook analyses reported in the paper; SB wrote the manuscript. All authors contributed to interpretation of data and commented on drafts of the paper. SB is guarantor.

\section{Competing interests}

The authors declare that they have no competing interests.

Received: 13 October 2010 Accepted: 30 March 2011

Published: 30 March 2011

\section{References}

1. Marmot M: Fair society, healthy lives: The Marmot Review London, University College London; 2010.

2. Commission on Social Determinants of Health: Closing the gap in a generation: Health equity through action on the social determinants of health. Final report of the Commission on Social Determinants of Health Geneva, World Health Oranisation; 2009.

3. Australian Government, Preventative Health Taskforce: Australia: The Healthiest Country by 2020 - National Preventative Health Strategy - Overview; 2009 [http://www.health.gov.au/internet/preventativehealth/publishing.nsf/ Content/AEC223A781D64FF0CA2575FD00075DD0/\$File/nphs-overview.pdf], Accessed June 2010

4. Jefferis BJMH, Power C, Hertzman C: Birth weight, childhood economic environment, and cognitive development in the 1958 British birth cohort study. BMJ 2002, 325:305.

5. Power C, Jefferis BJ, Manor O, Hertzman C: The influence of birthweight and socioeconomic position on cognitive development: does early home and learning environment modify their effects? J Pediatr 2006, 148(1):54-61.

6. Kuh D, Power C, Biane D, Bartley M: Social pathways between childhood and adult health. In A Lifecourse Approach to Chronic Disease. Edited by: Kuh D, Ben-Shlomo Y. Oxford: Oxford University Press; 1998:169-198.

7. O'Campo P, Xue X, Wang MC, Caughy M: Neighbourhood risk factors for low birthweight in Baltimore: a multilevel analysis. Am J Public Health 1997, 87(7):1113-1118.

8. Pattenden S, Dolk H, Vrijheid M: Inequalities in low birthweight: parental social class, area deprivation, and "lone mother" status. J Epidemiol Community Health 1999, 3(6):355-358.

9. Buka SL, Brennan RT, Rich-Edwards JW, Raudenbush SW, Earls F: Neighbourhood support and the birthweight of urban infants. Am J Epidemiol 2003, 157(1):1-8.

10. Moser K, Li L, Power C: Social inequalities in low birth weight in England and Wales: trends and implications for future population health. J Epidemiol Community Health 2003, 57(9):687-691.

11. Dibben C, Sigala M, Macfarlane A: Area deprivation, individual factors and low birthweight in England: is there eveidence of an "area effect"? Epidemiol Community Health 2006, 60(12):1053-1059.

12. Gissler M, Rahkonen O, Arntzen A, Cnattingius S, Nybo Andersen A-M: Trends in socio-economic differences in Finnish perinatal care 19912006. J Epidemiol Community Health 2009, 63(6):420-425.

13. Pattenden S, Casson K, Cook S, Dolk H: Geographic variation in infant mortality, stillbirth and low birth weight in Northern Ireland, 1992-2002. J Epidemiol Community Health 2010, [published online ahead of print 30 August 2010]
14. Janevic T, Stein CR, Savitz DA, Kaufman JS, Mason SM, Herring AH: Neighbourhood deprivation and adverse outcomes among diverse ethnic groups. Ann Epidemiol 2010, 20(6):445-451.

15. Khashan AS, McNamee R, Abel KM, Pedersen MG, Webb RT, et al: Reduced infant birthweight consequent upon maternal exposure to severe life events. Psychosomatic Medicine 2008, 70(6):688-694.

16. Nkansah-Amankra S, Luchok KJ, Hussey JR, Watkins K, Liu X: Effects of maternal stress on low birthweight and preterm birth outcomes across neighbourhoods of South Carolina, 2000-2003. Matern Child Health J 2010, 14(2):215-226.

17. Zhu P, Tao F, Hao J, Sun Y, Jiang X: Prenatal life events stress: implications for preterm birth and infant birthweight. Am J Obstet Gynecol 2010, 203(1):34.e1-8.

18. Janssen PA, Hot VL, Sugg NK, Emanuel I, Critchlow CM, Henderson AD: Intimate partner violence and adverse pregnancy outcomes: a population based study. Am J Obstet Gynecol 2003, 188(5):1341-7.

19. Silverman JG, Decker MR, Reed E, Raj A: Intimate partner violence victimization prior to and during pregnancy among women residing in 26 US states: associations with maternal and neonatal health. Am J Obstet Gynecol 2006, 195(1):140-148.

20. McFarlane J, Parker B, Soeken K: Abuse during pregnancy: associations with maternal health and infant birthweight. Nursing Research 1996, 45(1):37-42.

21. Campbell JC: Health consequences of intimate partner violence. Lancet 2002, 359:1331-1336

22. Rondó PH, Ferreira RF, Nogueira F, Ribeiro MC, Lobert H, Artes R: Maternal psychological stress and distress as predictors of low birth weight, prematurity and intrauterine growth retardation. European J Clin Nutrition 2003, 57(2):266-272

23. Hosseini SM, Biglan MW, Larkby C, Brooks MM, Gorin MB, Day NL: Trait anxiety in pregnant women predicts offspring birth outcomes. Paediatr Perinatal Epidemiol 2009, 23(6):557-566.

24. Kramer MS, Séguin L, Lydon J, Goulet L: Socio-economic disparities in pregnancy outcome: why do the poor fair so poorly? Paediatr Perinatal Epidemiol 2000, 14(3):194-210.

25. Laws P, Sullivan EA: Australia's mothers and babies 2007 Perinatal Statistics Series No. 23. Cat. No. PER 48, Sydney: AlHW National Perinatal Statistics Unit; 2009 .

26. Brown S, Lumley J: Antenatal care: a case of the inverse care law? Aust $J$ Public Health 1993, 17:95-102

27. Brown S, Lumley J: The 1993 Survey of Recent Mothers: issues in design, analysis and influencing policy. Int J Qual Health Care 1997, 9:265-277.

28. Brown S, Darcy M-A, Bruinsma F: Having a baby in Victoria 1989-2000. Aust N Z J Public Health 2002, 26(3):242-50.

29. Mullen PD, Carbonari JP, Tabak ER, Glenday MC: Improving disclosure of smoking by pregnant women. Am J Obstet Gynecol 1991, 165(2):409-13.

30. Whitehead NS, Brogan DJ, Blackmore-Prince C, Hill HA: Correlates of experiencing life events just before or during pregnancy. J Psychosom Obstet Gynaecol 2003, 24(2):77-86.

31. Paradies YC, Cunningham J: Development and validation of the Measure of Indigenous Racism Experience (MIRE). Int J Equity Health 2008, 7:9.

32. Stata Corporation: Stata Statistical Software Release 11 College Station, Texas: Stat Corporation; 2009

33. Cochrane A: Effectiveness and efficiency. Random reflections on health services London: Nuffield Provincial Hospitals Trust; 1972.

34. Lindmark $\mathrm{G}$, Berendes $\mathrm{H}$, Meirik $\mathrm{O}$ : Antenatal care in developed countries. Paediatr Perinatal Epidemiol 1998, 12(Supp 2):4-6.

35. Alexander GR, Kotelchuck M: Assessing the role and effectiveness of prenatal care: history, challenges, and directions for future research. Public Health Reports 2001, 116(4):306-316.

36. WHO: Regional Office for Europe (Health Evidence Network report). [http://www.who.int/social_determinants/thecommission/finalreport/en/ index.html], Accessed April 2010.

37. Carroli G, Villar J, Piaggio G, Khan-Neelofur D, Gülmezoglu M, Mugford M, Lumbiganon P, Bergsjo P, for the WHO Antenatal Care Trial Research Group: WHO systematic review of randomised controlled trials of routine antenatal care. Lancet 2001, 357:1565-70.

38. Sikorski J, Wilson J, Clement S, Das S, Smeeton N: A randomised controlled trial comparing two schedules of antenatal visits: the antenatal care project. BMJ 1996, 312:546-553. 
39. Villar J, Ba'aqeel H, Piaggio G, Lumbiganon P, Belizan JM, Al-Mazrou Y, Carroli G, Pinol A, Donner A, Langer A, Nigenda G, Mugford M, FoxRushby J, Hutton G, Bergsjo P, Bakketeig L, Berendes H, for the WHO Antenatal Care Trial Research Group: WHO antenatal care randomised trial for the evaluation of a new model of routine antenatal care. Lancet 2001, 357:1551-1564.

40. Lumley J, Chamberlain C, Dowswell T, Oliver S, Oakley L, Watson L: Interventions for promoting smoking cessation during pregnancy. Cochrane Database of Systematic Reviews 2009, , 3: CD001055.

41. Newton RW, Hunt LP: Psychosocial stress in pregnancy and its relation to low birth weight. BMJ 1984, 288:1191-94.

42. Kingston D, Heaman M, Fell D, Dzakpasu S, Chalmers B: Factors associated with perceived stress and stressful life events in pregnant women: findings from the Canadian Maternity Experiences Survey. Matern Child Health J 2010, [published online ahead of print 17 December 2010].

43. Olson JE, Shu XO, Ross JA, Pendergrass T, Robison LL: Medical record validation of maternally reported birth characteristics and pregnancyrelated events: a report from the Children's Cancer Group. Am J Epidemiol 1997, 145(1):58-67.

44. Lansakara N, Brown S, Flood M, Gartland D: Congruity between maternal recall of obstetric events and hospital medical records. J Paed Child Health 2010, 46(Suppl 1):A129.

45. Kerber KJ, de Graft-Johnson JE, Bhutta ZA, Okong P, Starrs A, Lawn JE: Continuum of care for maternal, newborn, and child health: from slogan to service delivery. Lancet 2007, 370:1358-69.

46. NICE clinical guideline 110: Pregnancy and complex social factors: a model for service provision for pregnant women with complex social factors. 2010 [http://www.nice.org.uk/guidance], Accessed 24 September 2010.

47. Ekman B, Pathmanathan I, Liljestrand J: Integrating health interventions for women, newborn babies and children; a framework for action. Lancet 2008, 372:990-1000.

48. Frenk J: Reinventing primary health care: the need for systems integration. Lancet 2009, 374:170-173.

Pre-publication history

The pre-publication history for this paper can be accessed here: http://www.biomedcentral.com/1471-2458/11/196/prepub

doi:10.1186/1471-2458-11-196

Cite this article as: Brown et al:: Stressful life events, social health issues and low birthweight in an Australian population-based birth cohort: challenges and opportunities in antenatal care. BMC Public Health 2011 11:196.

\section{Submit your next manuscript to BioMed Central and take full advantage of:}

- Convenient online submission

- Thorough peer review

- No space constraints or color figure charges

- Immediate publication on acceptance

- Inclusion in PubMed, CAS, Scopus and Google Scholar

- Research which is freely available for redistribution 